\title{
PENGOLAHAN HASIL PERKEBUNAN UNTUK PENINGKATAN EKONOMI MASYARAKAT DESA WOLOGAI TENGAH KECAMATAN DETUSOKO KABUPATEN ENDE
}

\author{
Melania Priska ${ }^{1)}$, Natalia Peni ${ }^{2)}$, Ludovicus Carvallo ${ }^{2)}$ \\ ${ }^{1)}$ Program Studi Pendidikan Biologi Universitas Flores \\ ${ }^{2}$ Program Studi Pendidikan Matematika Universitas Flores \\ E-mail:pika87cutes@gmail.com ${ }^{1)}$ nataliapeni27@gmail.com ${ }^{2)}$ \\ ludovicuscarvallo@gmail.com ${ }^{3)}$
}

\begin{abstract}
The KKN-PPM program aims to improve knowledge, skills, and economy of Central Wologai community about processing coffee and candlenut became ginger coffee and hazelnut oil are of high selling value. Method of implementation the KKN-PPM program is workshops both of technical and management aspects also marketing, the form were: workshop how to make ginger coffee and hazelnut oil; workshop enterpreuner motivation; home industry management workshops and product marketing. These activities was shown that the workshop can improve community knowledge and skills. Moreover, the community can also entrepreneurship home industry of ginger coffee and hazelnut oil as parcel characteristical in Central Wologai village. The products of the ginger coffee and candlenut from home industry can improve the economy of the community and provide employment for the community in Central Wologai village.
\end{abstract}

Keywords: Coffee, Hazelnut, Home Industry, Workshop

\begin{abstract}
Abstrak
Program KKN-PPM bertujuan untuk meningkatkan pengetahuan, ketrampilan, dan ekonomi masyarakat desa Wologai Tengah tentang pengolahan buah kopi dan kemiri menjadi kopi jahe dan minyak kemiri yang bernilai jual tinggi. Adapun metode pelaksanaan program KKN-PPM ini adalah berupa workshop pada aspek teknis maupun manajemen dan pemasarannya, dalam bentuk: workshop pembuatan kopi jahe dan minyak kemiri; workshop enterpreuner motivation; workshop manajemen home industry dan pemasaran hasil produksi. Dari kegiatan tersebut menunjukkan bahwa workshop dapat meningkatkan pengetahuan dan ketrampilan masyarakat. Selain itu, masyarakat juga dapat berwirausaha secara home industry kopi jahe dan minyak kemiri sebagai buah tangan khas desa Wologai Tengah. Hasil dari home industry kopi jahe dan minyak kemiri dapat meningkatkan ekonomi masyarakat dan membuka lapangan pekerjaan bagi masyarakat desa Wologai Tengah.
\end{abstract}

Kata Kunci: Kopi, Kemiri, Workshop, Home Industry.

\section{PENDAHULUAN}

Desa Wologai Tengah adalah salah satu desa di kecamatan Detusoko Kabupaten Ende, dengan luas wilayah seluas $64 \mathrm{~km}^{2}$ dan total jumlah penduduk sebanyak 908 jiwa. Jarak dari ibu kota kabupaten ke desa Wologai Tengah kecamatan Detusoko adalah $\pm 40-44 \mathrm{~km}$, dimana lama jarak tempuh sekitar $\pm 1-1,5$ jam dengan menggunakan kendaraan bermotor. Desa ini merupakan desa wisata hasil pemekaran dari desa induk Wologai, yang dulunya beribukota di Ekoleta 
kecamatan Detusoko. Jarak desa Wologai Tengah dari ibu kota kecamatan $\pm 11 \mathrm{~km}$.

Mata pencaharian masyarakat di desa Wologai Tengah mayoritas adalah petani, dan sisanya berprofesi sebagai guru serta pensiunan. Sebagai desa yang kegiatan pembangunannya berbasis mandiri pada bidang pertanian, desa Wologai Tengah merupakan desa penghasil kopi dan kemiri. Kopi merupakan tanaman pohon bertubuh tegak, bercabang, dan berakar tunggang yang hanya dapat hidup pada daerah dataran tinggi $\pm 1.000-2.100$ meter dpal, dengan curah hujan berkisar antara 1.000 - $2.000 \mathrm{~mm} / \mathrm{tahun}$ dan suhu lingkungan $16-28^{\circ} \mathrm{C}$ (Evizal 2013). Kemiri merupakan pohon berdaun lebar dengan ketinggian hingga $20 \mathrm{~m}$ dan mempunyai diameter batang setinggi dada hingga $90 \mathrm{~cm}$. Pohon kemiri tumbuh pada daerah dataran tinggi yaitu sekitar $1200 \mathrm{~m}$ dpal. Tanaman kemiri tumbuh pada berbagai jenis tanah baik jenis tanah yang subur maupun kurang subur, dengan curah hujan setiap tahun berkisar antara 640-4290 mm. Suhu yang cocok untuk pertumbuhan kemiri adalah $8-30^{\circ} \mathrm{C}$ yaitu pada daerah yang beriklim hujan topis (Pranowo \& Rusli 2012).

Tanaman kopi dan kemiri merupakan salah satu komoditas unggulan di desa Wologai Tengah, dengan jumlah produksi pertahun mencapai angka 12-13 ton untuk kopi dan 30-32 ton untuk kemiri. Besarnya produksi kopi dan kemiri di desa Wologai Tengah ini didukung oleh sifat fisika dan kimia tanah, curah hujan, dan suhu rata-rata harian, serta ketinggian tanah di desa Wologai Tengah dari permukaan air laut yang sesuai dengan syarat tumbuh tanaman kopi dan kemiri. Produksi hasil kopi dan kemiri tersebut tidak sebanding dengan harga jual yang dipasarkan oleh masyarakat desa Wologai Tengah. Dimana harga jual perkilogram sebesar Rp. 35.000,- untuk kopi dan Rp. 30.000,- untuk kemiri (Tim Penyusun RPJM 2016). Padahal jika kopi dan kemiri diolah menjadi produk yang bernilai jual tinggi seperti kopi jahe dan minyak kemiri, akan meningkatkan nilai jual yang berdampak pada peningkatan ekonomi masyarakat desa Wologai Tengah.

Kopi jahe mempunyai banyak manfaat bagi kesehatan, diantaranya bagi seseorang yang melakukan latihan fisik berat, kopi jahe dapat meredakan keluhan sakit otot dan kelelahan.Selain itu, adanya campuran jahe pada kopi dapat menghangatkan tubuh pada musim dingin; sebagai obat flu dan masuk angin; serta mengurangi pertumbuhan sel kanker, hingga asma, dan pencegahan berbagai jenis penyakit lainnya (Tupamahu, 2014; Mardhatilah, 2015). Minyak kemiri bermanfaat untuk menjaga kelembapan dan melindungi kulit dari sinar matahari; menjaga kesehatan dan kesuburan rambut serta kulit kepala; mengobati pembengkakan pada sendi; menghilangkan pegal linu; mengobati sakit gigi dan sariawan; mengobati ambeien dan sembelit; serta mengobati bisul dan mengatasi demam (Arlene, dkk. 2010; Lumbantoruan, dkk. 2014). 
Berdasarkan hasil wawancara dan observasi dengan masyarakat desa Wologai Tengah ditemukan bahwa masyarakat belum mengetahui manfaat dari kopi jahe dan minyak kemiri. Hal ini dikarenakan: 1). kurangnya pengetahuan masyarakat terhadap teknik pengolahan buah kopi dan kemiri menjadi kopi jahe dan minyak kemiri; 2). masyarakat kurang termotivasi dalam berwirausaha; 3). lemahnya pengetahuan masyarakat terhadap manajemen kewirausahaan dan dalam memasarkan hasil produksi. Dari permasalahan tersebut maka perlu diadakan kegiatan workshop pembuatan kopi jahe dan minyak kemiri.

\section{METODE PELAKSANAAN}

Metode pelaksanaan program $\mathrm{KKN}$ PPM dalam kegiatan pengolahan hasil perkebunan ini berupa workshop pada aspek teknis maupun manajemen dan pemasarannya di desa Wologai Tengah. Peserta yang mengikuti workshop adalah petani kopi, jahe dan kemiri yang dilaksanakan selama tiga (3) hari. Pada waktu workshop berlangsung dibagi dalam dua bagian kegiatan yakni:

a. Hari pertama: penjelasan materi tentang karakter umum tanaman kopi, jahe, dan kemiri; kandungan gizi dan non gizi kopi, jahe, dan kemiri; manfaat dan kegunaan kopi, jahe, dan kemiri; prosedur pembuatan kopi jahe dan minyak kemiri, motivasi berwirausaha, dan manajemen pemasaran produk home industry. b. Hari kedua: praktek pembuatan kopi jahe.

c. Hari ketiga: praktek pembuatan minyak kemiri.

\section{HASIL DAN PEMBAHASAN}

Program pengabdian KKN-PPM dilakukan dengan beberapa tahapan, yakni:

a) Persiapan dan Pembekalan

Pembekalan KKN-PPM Universitas Flores dilaksanakan pada tanggal 05 Juli 2018 dengan materi yang diberikan kepada mahasiswa adalah sebagai berikut: (a). produksi kopi jahe dan minyak kemiri (Krisnawati dkk., 2011; Mardhatilah, 2015; Novianti dkk., 2016; Parwati \& Suparno, 2017); (b). motivasi berjiwa wirausaha (Rosmiati dkk., 2015; Aidha, 2016; Austhi, 2017); dan (c). strategi manajemen home industry dan pemasaran produk (Diniaty \& Agusrinal, 2014; Sunarsih \& Umar, 2015; Rochdiani dkk., 2018).

b) Pelaksanaan

Pelaksanaan kegiatan KKN-PPM Universitas Flores adalah sebagai berikut: (a). pembekalan mahasiswa peserta KKNPPM tahun akademik 2017/2018; (b). sosialisasi program kerja mahasiswa KKN-PPM kepada masyarakat desa Wologai Tengah; (c). penyiapan sarana dan prasarana yang mendukung kegiatan KKN-PPM; (d). peningkatan pengetahuan dan ketrampilan mitra melalui workshop; (e). pelaksanaan program kerja KKNPPM; (f). monitoring dan evaluasi program KKN-PPM; dan (g).rencana 
tindak lanjut program kerja KKN-PPM (Sapar, dkk. 2017).

Pelaksanaan program kerja KKNPPM terencana dan terlaksana dengan baik lewat kerjasama antara mahasiswa, dosen pembimbing lapangan, dan warga

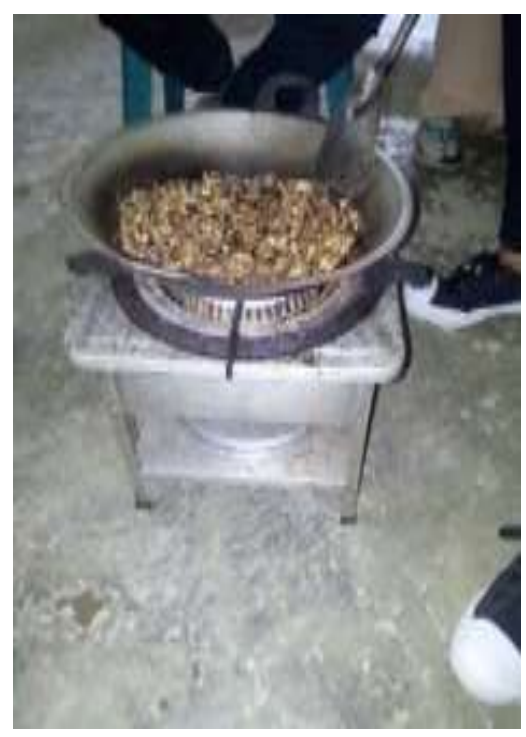

(a) masyarakat desa Wologai Tengah. Kegiatan pembuatan kopi jahe dan minyak kemiri oleh mahasiswa dan masyarakat dapat ditunjukkan pada gambar 1a dan $1 \mathrm{~b}$.

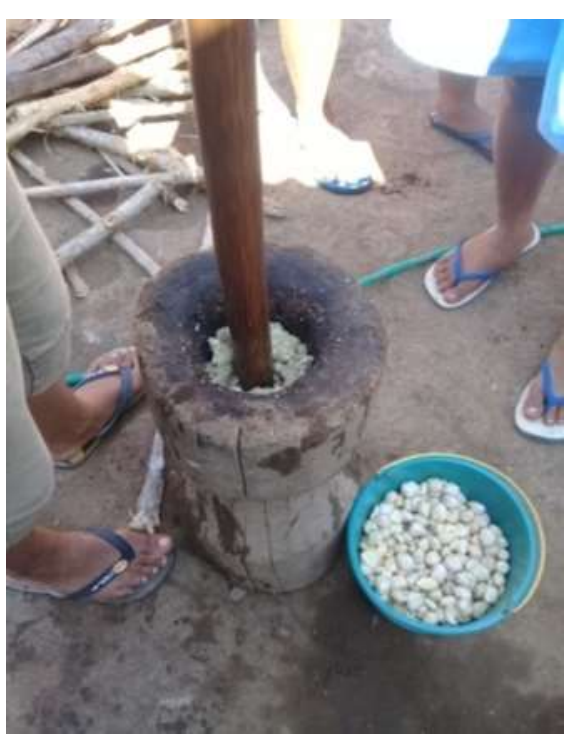

(b)

Gambar 1. a.) Pembuatan Kopi Jahe; b.) Pembuatan Minyak Kemiri

c) Monitoring dan Evaluasi

Hasil monitoring dan evaluasi dari dosen pembimbing lapangan terhadap program KKN-PPM yang dilakukan oleh mahasiswa bersama dengan masyarakat terkait dengan pembuatan kopi jahe dan minyak kemiri, diperoleh bahwa pengolahan kopi dan buah kemiri ini sangat efisien dan efektif karena mudah untuk dilakukan;tidak membutuhkan modal yang besar; serta waktu pengerjaan yang relatif singkat untuk menghasilkan produk olahan yang berdaya jual tinggi. Pemasaran kopi jahe dan minyak kemiri sebagai salah satu bentuk peluang berwirausaha, ternyata memberikan dampak positif bagi peningkatan perekonomian masyarakat desa Wologai Tengah dan membuka lapangan pekerjaan bagi masyarakat.

d) Rencana Tindak Lanjut Program Kerja KKN-PPM

Setelah pelaksanaan program kerja KKN-PPM, maka untuk menunjang keberlanjutan dan pengembangan program dilakukan rencana tindak lanjut, yakni: (a). membangun jejaring dengan unit usaha kopi jahe dan minyak kemiri; (b). mengajukan pembinaan pengembangan usaha dan membangun galeri pemasaran 
melalui dinas perindustrian dan perdagangan kabupaten Ende; dan (c). menjembatani masyarakat dengan pusat perijinan terpadu kabupaten Ende, agar masyarakat memiliki ijin usaha berbadan hukum.

\section{PENUTUP}

a) Kesimpulan

Adapun kesimpulan dari program KKN-PPM Universitas Flores tahun akademik 2017/2018, yakni:

1. Kegiatan KKN-PPM tentang workshop pembuatan kopi jahe dan minyak kemiri dapat meningkatkan pengetahuan, ketrampilan, dan menghasilkan produk khas desa Wologai Tengah yang dapat meningkatkan pendapatan ekonomi masyarakat desa.

2. Menjadi buah tangan para wisatawan yang berkunjung ke desa Wologai Tengah.

b) Saran

Setelah melakukan program KKNPPM, diharapkan:

1. Masyarakat tetap mempertahankan dan mengembangkan home industry kopi jahe dan minyak kemiri dalam peningkatan ekonomi rumah tangga secara berkelanjutan.

2. Desa Wologai Tengah dan Universitas Flores dapat menjadi mitra dalam pengembangan usaha kopi jahe dan minyak kemiri.

\section{DAFTAR PUSTAKA}

Aidha, Z. 2016. Pengaruh Motivasi terhadap Minat Berwirausaha Mahasiswa Fakultas Kesehatan Masyarakat Universitas Islam Negeri Sumatera Utara. Jurnal Jumantik 1 (1): 42-59.

Arlene, A., Suharto, I., \& Jessica. 2010. Pengaruh Temperatur dan Ukuran Biji terhadap Perolehan Minyak Kemiri pada Ekstraksi Biji Kemiri dengan Penekanan Mekanis. Prosiding Seminar Nasional Teknik Kimia "Kejuangan": Pengembangan Teknologi Kimia untuk Pengolahan Sumber Daya Alam Indonesia. ISSN: 1693- 4393.

Austhi, D. 2017. Motivasi Berwirausaha dan Kesuksesan Berwirausaha pada Wirausahawan Wanita Anne Avanite. AGORA 5 (1): 1-8.

Diniaty, D. \& Agusrinal. 2014. Perancangan Strategi Pemasaran pada Produk Anyaman Pandan. Jurnal Sains, Teknologi dan Industri 11 (2): 175-184.

Evizal, R. 2013. Etno-Agronomi Pengelolaan Perkebunan Kopi di Sumberjaya Kabupaten Lampung Barat (Riview). Agrotrop 3 (2): 1 12.

Krisnawati, H., Kallio, M., Kanninen, M. 2011. Aleurites moluccana (L.) Willd.: Ekologi, Silvikultur dan Produktivitas. Bogor: CIFOR. 
Lumbantoruan, D., Rohanah, A., \& Rindang, A. 2014.Uji Pengaruh Suhu Pemanasan Biji Kemiri dengan Menggunakan Oil Press Tipe Ulir terhadap Rendemen dan Mutu Minyak Yang Dihasilkan. Jurnal Rekayasa Pangan dan Pertanian2(3): 92-98.

Mardhatilah, D. 2015. Pengaruh Penambahan Konsentrasi Jahe dan Rempah pada Pembuatan Sirup Kopi. Agroteknose 6(2): 55-61.

Novianti, F., Wijayanti, F., Carolina. 2016. Analisis Usaha Pengolahan Kopi Jahe Skala Mikro. Studi Kasus: Unit Kopi Rakyat di Wewewa Tengah - Sumba Barat Daya. Seminar Nasional IENACO pp. 726 - 732. ISSN: 2337 - 4349.

Parwati, L. D. \& Suparno. 2017. Pengaruh Massa Kemiri terhadap Volume dan Karakterisasi Minyak Kemiri Hasil Pengolahan Tradisional sebagai Bahan Dasar Biofuel. Jurnal Fisika 6 (5): 378-384.

Pranowo, D. \& Rusli. 2012. Penampilan Sifat Agronomi Tanaman Kemiri Sunan [Reutealis trisperma (Blanco) Airy Shaw] yang Berasal dari Grafiting dan Biji. Buletin Riset: Tanaman Rempah dan Aneka Tanaman Industri 3 (3): 193 - 200.

Rochdiani, D., Kusumo, R. A. B., Wiyono, S. N., Qanti, S. R., Sadeli, A. H.
2018. Manajemen Usaha Home Industry Desa Sindangsari Kecamatan Sukasari Kabupaten Sumedang. Dharmakarya: Jurnal Aplikasi Ipteks untuk Masyarakat 7 (1): 51-55.

Rosmiati, Junias, D. T. S., Munawar. 2015. Sikap, Motivasi, dan Minat Berwirausaha Mahasiswa. Jurnal Manajemen dan Kewirausahaan 17 (1): 21-30.

Sapar, Bustami, L., \& Munarka, A. H. 2017. Pengabdian KKN-PPM di Desa Lagego Kecamatan Burau Kabupaten Luwu Timur. Resona Jurnal Ilmiah Pengabdian Masyarakat 1(1):1-5.

Sunarsih, L. \& Umar, H.M. S. 2015. Strategi Pemasaran Home Industry Pengrajin Anyaman Bambu di Desa Gintangan Kecamatan Rogojampi Kabupaten Banyuwangi. Jurnal Pendidikan Ekonomi IX (2): 57-68.

Tim Penyusunan RPJM. 2016. RPJM Desa Wologai Tengah Kecamatan Detusoko Kabupaten Ende. Wologai Tengah: Kantor Desa Wologai Tengah.

Tupamahu, Y. M. 2014. Analisis Usaha Pengolahan Kopi Jahe Instan Di Ternate. Jurnal Ilmiah Agribisnis dan Perikanan 7(2): 68-74. 